\title{
Performance Analysis of Dispersion Compensation Schemes with Delay Line Filter
}

\author{
Kasthuri Palanichamy, Prakash Poornachari, Ganesh Madhan M \\ Anna University, MIT Campus, Department of Electronics Engineering, Chennai, Tamilnadu, \\ India
}

\begin{abstract}
Optical communication is an effective system to achieve the high-speed data transmission for long distance. The main factor that affects the optical communication is dispersion. Dispersion leads to reduction of the system performance and Q-factor. Dispersion can be compensated using various techniques. Major techniques are compensation using Dispersion Compensating Fiber (DCF), Fiber grating technique, and Delay Line Filter (DLF). Analysis has been performed on the Bit Error Rate (BER) and Quality Factor (Q-Factor) of various schemes based on Eye Opening Penalty (EOP) with BER analyzer for dispersion compensation. It has been concluded that Impulse Invariant Response (IIR) based DLF at average results in 50\% of better compensation when compared Fiber Bragg Grating and DCF based compensation techniques. The power of the received signal when transmitted at $0 \mathrm{dBm}$ for $120 \mathrm{kms}$ is $-12.325 \mathrm{dBm}$ which is the optimum power in which the signal can be received without distortion.
\end{abstract}

\section{Analiza učinkovitosti disperzijskih kompenzacïskih načrtov z linijskim kasnilnim sitom}

\begin{abstract}
Izvleček: Optične komunikacije so učinkovit sistem za hiter prenos podatkov na dolge razdalje. Glavni dejavnik, ki vpliva na optične komunikacije je razpršitev (disperzija). Razpršitev vodi v zmanjšanje sistemskih zmogljivosti in faktorja Q. Razpršitev je mogoče kompenzirati z različnimi tehnikami. Glavne kompenzacijske tehnike so kompenzacija z uporabo vlaken za kompenzacijo disperzije, tehnike vlakenske periodične strukture in linijskim kasnilnim sitom. Opravljena je bila analiza pogostosti bitne napake in faktorja kvalitete (faktor Q) različnih načrtov kompenzacije disperzije, ki temelji na odprtosti očesnega diagrama z analizatorjem pogostosti bitnih napak. Ugotovljeno je bilo, da linijsko kasnilno sito z neskončnim impulznim odzivom v povprečju doseže 50\% boljšo kompenzacijo v primerjavi s kompenzacijskima tehnikama vlakenske Braggove periodične strukture in vlakna za kompenzacijo disperzije. Pri oddajni moči 0 dBm je moč sprejetega signala po 120 kilometrih -12.325 dBm, kar je optimalna moč pri kateri je mogoče signal sprejeti brez popačenja.
\end{abstract}

Ključne besede: linijsko kasnilno sito, BER, factor Q, kompenzacija razpršitve

*Corresponding Author's e-mail:prakashp79@gmail.com,prakashp_mit@annauniv.edu

\section{Introduction}

Optical communication is the methodology that allows light through an optical fiber for transmitting information from one place to another. The three basic components for optical transmission systems are fiber medium, light source and light detector. The communication channel must allow the optical signal to reach the receiver without any distortion by the channel. In- formation passes through the optical fiber experiences dispersion and attenuation which is the main factor that affects the communication. Mostly the lightwave system uses optical fibers as the communication channel. The reason is that silica fiber can transmit light with very few losses. Even then, optical power reduces to only $1 \%$ after $100 \mathrm{~km}$. Hence, fiber losses are always an important design issue. This can be reduced by the 
use of a repeater or amplifier. Fiber dispersion is also an important issue which should be taken care during the fiber designing. The transmitted signal will be degraded if optical pulses spread significantly outside their allocated bit slot. It becomes difficult to recover the original signal with high accuracy [1]. The optical signal in the fiber experiences various non-linear effects like Raman scattering and Kerr Effect. They both limit the received signal in fibers. Also, the signal experiences various dispersion like chromatic dispersion and polarization mode dispersion, which makes fibers not practical for long distance communication [2]. Recently, research in dispersion compensation of fibers have gained momentum with increase in demand for high bandwidth communication systems. With increase in need for high capacity and high speed communication systems for future, dispersion compensation techniques for long distance fiber communication is now necessary [3]. Fiber-Optic dispersion compensation on optical transmission systems is studied using various techniques. In order to improve the overall system efficiency and to reduce the dispersion which leads to transmission degradation, several dispersion compensation techniques were proposed [4]. The techniques which act as the solution for dispersion compensation is broadly classified as: Dispersion Compensation Fibers (DCFs), High-Order Mode (HOM) Fiber, Fiber Bragg Gratings (FBG), and delay line filter. Li.,L. et.al discussed about the use of ring resonators acting as passband microwave photonic filter in order to perform dispersion compensation [5]. Poornachari, P. et.al discussed about using Side Couple Integrated Space Sequence of Resonator (SCISSOR) acting as delay line based All Pass Filter for dispersion compensation [6]. Also, Dispersion is compensated at the receiver end using Digital Signal Processing techniques. K. Zhong et.al discusses the application of signal processing at receiver end for dispersion compensation in short Optical communications [7]. Kakkar, A et.al discusses the application of digital signal processing at both receiver end and at transmitter side for dispersion compensation [8]. Dispersion is also compensated in electronics means by pre-processing the signal and compensating it for dispersion at the transmitter end by substituting the signal using $2 n$ bit look up table [9]. Also M. A. Ilgaz, et al., discussed a flexible approach to combating chromatic dispersion in a centralized 5G network which will be focused in the future work of this paper [10].

In this paper, we have designed a novel DLF IIR filter and the performance of IIR based DLF for dispersion compensation is compared with Dispersion Compensation Fiber and Fiber Bragg grating. The above mentioned techniques under goes various disadvantages like manufacturing cost, complex design, reduced flexibility, mainly length of the fiber. The distance of 120 kms can be covered using DLF IIR filter. Also it increases the speed of execution. The computational complexity is greatly reduced by this method and improves the performance of the interlever. The main advantage of this method is that it can be used to design the band pass filter without specifying the transition regions.

\section{Dispersion compensation techniques}

In an optical medium Dispersion Compensating Fiber (DCF) provides a large negative value of chromatic dispersion at the operating wavelength. Depending on the placement location of dispersion compensation fiber it is classified as pre, post and mix compensation. Dispersion compensation fiber is used to achieve the perfect compensation. The condition for perfect dispersion compensation is [11]:

$$
D_{S M F}=L_{D C F} D_{D C F}
$$

Where $L_{S M F}$ the length of the Single Mode Fiber (SMF) in the link, $L_{D C F}$-the length of the DCF is used to obtain dispersion compensation, while $D_{S M F}$ and DDCF gives the dispersion values for the single mode fiber and dispersion compensation fiber respectively. The pulse spread due to chromatic dispersion is given [11] in the equation (2).

$$
\Delta t=L D(\lambda) \Delta \lambda
$$

Where, $\mathrm{t}$ is Pulse Spread (ps); $\mathrm{L}$ defines Fiber Length $(\mathrm{km}) ; D(\lambda)$ denotes Chromatic Dispersion factor (ps/ $\mathrm{nm}-\mathrm{km}) ; \lambda$ represents Operating Wavelength $(\mathrm{nm}) ; \Delta \lambda$ is Spectral Width of the transmitter output $(\mathrm{nm})$

\subsection{Pre-compensation Technique}

In pre compensation technique the single mode fiber is placed after the dispersion compensation fiber. The dispersion compensation fiber experiences the positive dispersion and while single mode fiber which already has negative dispersion when they connect together the dispersion gets compensated. So that the data in the receiver experience no distortion [12-15].

\subsection{Post-compensation Technique}

In post compensation technique the single mode fiber is placed before the dispersion compensation fiber. The single mode fiber produces the negative dispersion whereas dispersion compensation fiber which already has positive dispersion when connected together gets compensated and reaches the receiver without any distortion. The post compensation technique consists of a 
receiver with pin diode and BER analyzer, and transmitter with laser source. The transmission channel has single mode fiber followed by DCF. In the post compensation technique the dispersion is compensated at the receiver end [16-17].

\subsection{Mix compensation Technique}

Mix compensation is a technique in which dispersion is compensated in both transmitter and receiver side where the dispersion compensation fiber is placed before and after the single mode fiber which results in increases performance compared with other compensation technique [20-22]. Figure 1 shows the block diagram of Mix Compensation technique as pre and post compensation can be achieved by modifying mix compensation. By considering the various types of nonlinear effects based on optical transmission, the Erbium Doped Fiber Amplifier (EDFA) system is utilized. According to the placement of DCF and SMF, dispersion compensation using compensation fiber is analyzed.

\subsection{Fiber Bragg Grating}

A FBG is one of the methods of distributed Bragg reflector to reflect back the particular wavelength of light and transmit remaining. This is achieved by creating periodic variation in the refractive index of the fiber core [23].

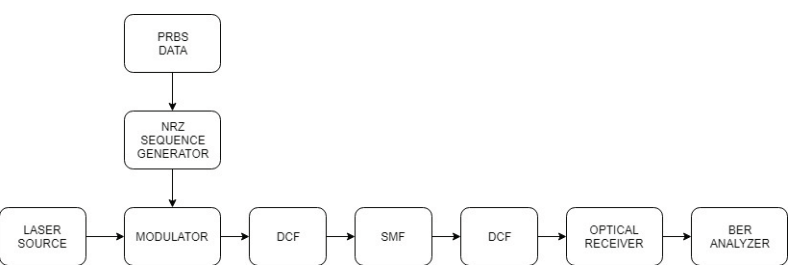

Figure 1: Block Diagram of Mix Compensation Technique

At each periodic refraction there is change in a small amount of reflected light. At a particular wavelength all the reflected light signals combine uniformly to one large reflection. This is referred to as the Bragg condition, and the wavelength at which the reflection occurs is known as the Bragg wavelength. The non-phase matched wavelengths are transparent fiber Bragg grating

The grating equation is [24],

$$
\Lambda\left(\sin \sin \theta_{i n}-\sin \theta_{d i}\right)=n \lambda
$$

Where $\Theta_{\text {in }}$ and $\Theta_{d i}$ are incident and diffracted angles.

The imprinted grating [24] can be represented as $n(z)=n_{c}+\delta n\left[1+\cos \frac{2 \pi z}{\Lambda}\right]$

where, $n_{c}$ is refractive index of core, $\delta_{n}$ is photo induced change in index

The reflection wavelength is given as $\lambda_{\text {Bragg }}=2 \Lambda n_{\text {eff }}$ and the peak reflectivity for the grating length of $L$ and the coupling coefficient $x$ is given by,

$R_{\text {max }}=\tanh ^{2}(x L)$

The full bandwidth in which the reflectivity [24] can have is

$\Delta \lambda=\frac{\lambda_{\text {Bragg }}^{2}}{\pi n_{\text {eff }} L}\left[(x L)^{2}+\pi^{2}\right]^{\frac{1}{2}}$

\subsection{Delay Line Filter}

Chromatic dispersion can be compensated using the optical filter in fiber communication. Optical communication is a way of transmitting the information by modulating the light signal with the information signal. The mathematical operation on a sampled, discretetime signal to reduce or enhance certain conditions of that signal is performed in the digital filter. Two types of digital filters are recursive filter and non-recursive filters [25]. Delay line recursive filter is analyzed here. These filters are realized in the optical domain which comprises unit delay, weight element and adders. The input field is splitted into $M+1$ different elements in turn will be delayed separately by multiples of unit delays. Filter order can be determined by the highest delay. The multiple copies of the input field are recombined in the final stage.

The input field,

$E_{i}=E_{o}(t) e^{j \omega t}$

The output field composite of

$E_{o}=b_{o} E_{i}+b_{1} e^{j \omega T_{1}} E_{i}+b_{2} e^{j \omega T_{2}}$

Thus, the filter transfer function will be

$H\left(e^{j \omega}\right)=\sum_{i=0}^{N} b_{i} e^{j \omega T_{o}}$

Setting $Z=e^{j \omega T_{0}}$, transform of the filter will be

$H(Z)=\sum_{i=0}^{N} b_{i} Z^{-i}$ 
The DLF with the source of $1550 \mathrm{~nm}$ is proposed in Figure 2 [26].

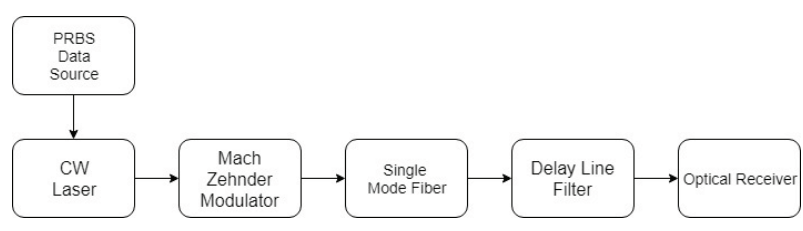

Figure 2: Optical link for system simulation

\section{Implementation of DCF}

Various Dispersion Compensation Modules (DCM) are implemented using Optisystem. Optisystem is a rapidly evolving software design tool that enables the user to design, test, and simulate the optical communication systems comprised of all optical components and also helps us to visualize the analysis for the optical link. Implementing realistic modeling of fiber-optic communication systems is more complex in which optisystem can offer a system level simulator for the design for the transmitter, channel, amplifier, and receiver models of the optical system. Initially compensation with dispersion compensation fiber is performed. Fiber-Optic dispersion compensation on optical transmission systems is studied using various techniques. In order to improve the overall system efficiency and to reduce the dispersion which leads to transmission degradation, several dispersion compensation techniques were proposed. Depending upon the placement of the dispersion compensation fiber the dispersion can be compensated pre, post and mix compensation method. The mix compensation portion is blocked in the layout. Transmitter system consists of the laser source, Non-Returnto-Zero (NRZ) waveform and Mach Zehnder modulator. NRZ waveform is generated from the binary values of Pseudo Random Binary Sequence (PRBS) at length of 128 bits, is provided to the Mach Zehnder modulator at a data rate of $10 \mathrm{Gbps}$. The communication system can be divided into three parts they are transmitter, receiver and channel.

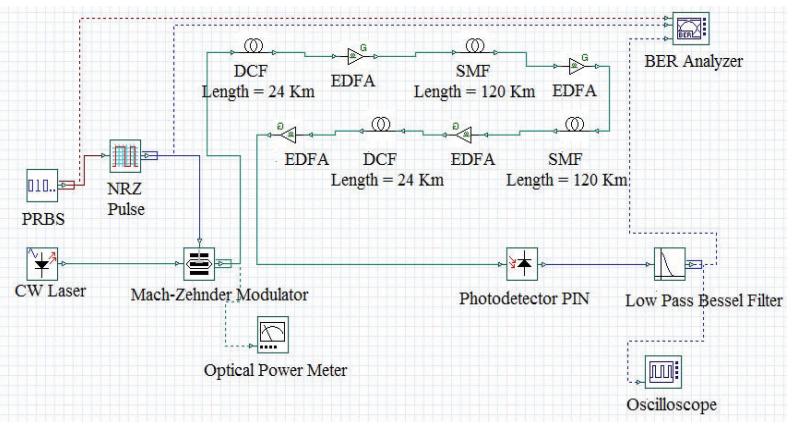

Figure 3: Simulation Layout of mix-Compensation Technique
The channel is the main area for the occurrence of the dispersion hence the compensation is mainly performed in the communication channel. As like the pre compensation technique the post compensation performs the same operation where the placement of the dispersion compensation fiber is after the SMF.

Figure 3 shows the simulation layout of the mix compensation technique. The mix compensation technique can be used for long distance communication. Since the dispersion is compensated in both the transmitter and the receiver side. This technique shows better performance compared to the pre and post compensation technique. Simulation layout shown in Figure 4 which clearly gives the arrangement of FBG.

The simulation of the DLF using IIR filter is given in Figure 5. Transmitter system consist of the laser source, NRZ waveform is generated from the binary values of PRBS at length of 128 bits, is provided to the Mach Zehnder modulator at a data rate of $10 \mathrm{Gbps}$.

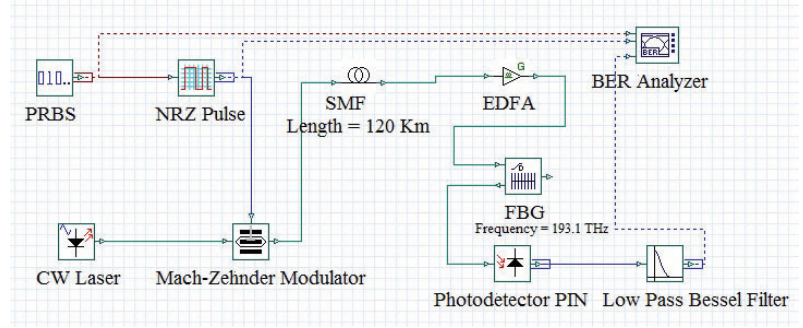

Figure 4: Simulation Layout of Fiber Bragg Grating

In which the BER and Q-factor can be analyzed using a BER analyzer. In this technique the dispersion is compensated using the delay line filter. The post compensation technique used in the DLF dispersion compensation, where the placement of delay line filters is followed by the single mode fiber.

The simulation of the DLF using IIR filter is given in Figure 5 from which the BER and Q-factor can be analyzed using the BER analyzer. In this technique the dispersion is compensated using the DLF. The post compensation technique used in the DLF dispersion compensation, where the placement of DLF is followed by the single mode fiber.

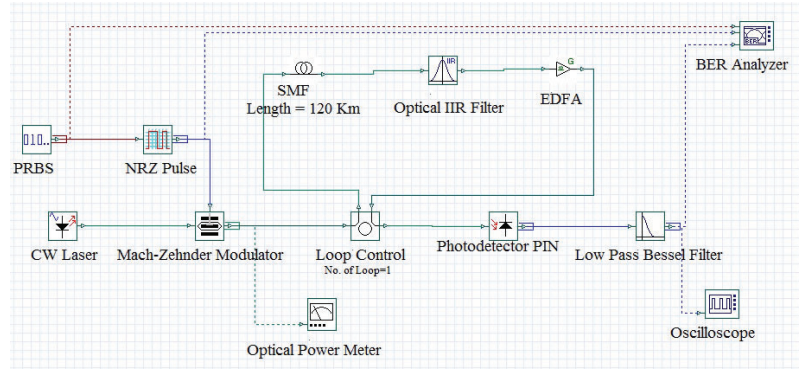

Figure 5: Simulation Layout of Delay line IIR Filter 


\section{Simulation results}

The simulations of each technique are shown in this session. $0 \mathrm{dBm}$ power is used for the transmission link. The results are analyzed at the receiver part which consist of a photo detector, electrical filter and BER analyzer where the eye pattern is analyzed. The inputs given to the BER analyzer are from PBRS at the length of 128 bits, NRZ and the output from low pass Bessel filter. Table 1 gives the BER pattern comparison of precompensation, post-compensation and mix-compensation. The Q-Factor and minimum BER for the compensation techniques are analyzed using BER analyzer. The Eye pattern for the simulation of pre, post and mix compensation techniques are given in Table 1.

Table 2 shows the performance comparison of Q-factor and Minimum BER. BER patterns are also analyzed using eye opening penalty which is shown in Table 1.

Table 1: Comparison of BER pattern for Pre, Post, Mix compensation techniques

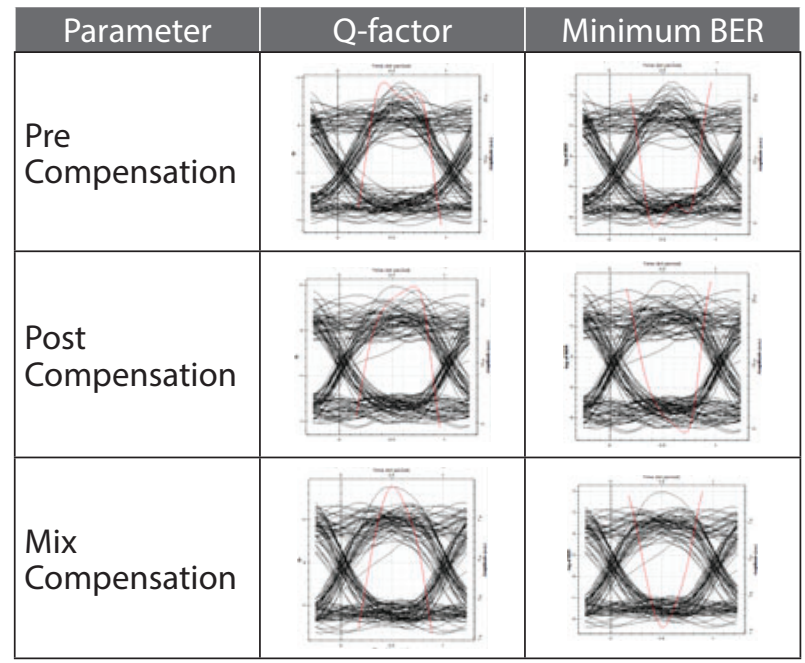

It is found that mix compensation gives better performance compared to the pre compensation and post compensation technique [26]. Also, the method of pre-compensation would not be suitable for systems that have variable distortion like polarization mode dispersion. Post compensation would be better equipped to handle variable sources of dispersion. But, having compensation at transmitter end and receiver end would result in better performance as seen above, but increase in performance also increases the cost of deployment of the system. Delay line based post compensation gives better performance than mixed form of compensation without the expense of increasing the cost of the system. From the comparison Table 2 the Q-factor and Min BER are also analyzed for various dispersion compensation techniques. It is clear form the result that the delay line IIR filter gives better performance.

Table 2: Comparison of Q-Factor and Minimum BER values

\begin{tabular}{|l|c|l|}
\multicolumn{1}{c|}{$\begin{array}{c}\text { Factors } \\
\text { Analyzed }\end{array}$} & Q- Factor & \multicolumn{1}{c|}{ Min BER } \\
\hline Pre Compensation & 4.89907 & $4.71181 \times 10^{\wedge}-7$ \\
\hline Post Compensation & 4.96922 & $3.26974 \times 10^{\wedge}-7$ \\
\hline Mix Compensation & 5.7533 & $4.23322 \times 10^{\wedge}-9$ \\
\hline FBG & 6.16313 & $3.56 \times 10^{\wedge}-10$ \\
\hline Delay Line IIR Filter & 11.08 & $6.8 \times 10^{\wedge}-29$ \\
\hline
\end{tabular}

Table 3: Comparison of received power with various dispersion compensation techniques.

\begin{tabular}{|l|l|}
\multicolumn{1}{c|}{$\begin{array}{c}\text { Compensation } \\
\text { Techniques }\end{array}$} & Received Power in $\mathrm{dBm}$ \\
\hline DCF - Pre Compensation & -13.120 \\
\hline DCF - Post Compensation & -12.109 \\
\hline DCF - Mix Compensation & -10.125 \\
\hline FBG & -17.235 \\
\hline Delay Line IIR Filter & -12.253 \\
\hline
\end{tabular}

Table 3. shows the received power when a NRZ signal is transmitted in a fiber of length $120 \mathrm{kms}$. Power penalty for Delay line IIR filter is similar to other compensation techniques. However, delay line IIR filter results in a much better BER and Q-Factor when compared with other compensation techniques. Though DCF based mixed compensation technique produces better results when related with power, mix compensation requires use of two identical compensation components at the transmitter and receiver end which increases the complexity of the system. From the values of BER and Q-Factor, it can be seen that delay line IIR filter based dispersion compensation produces better results with

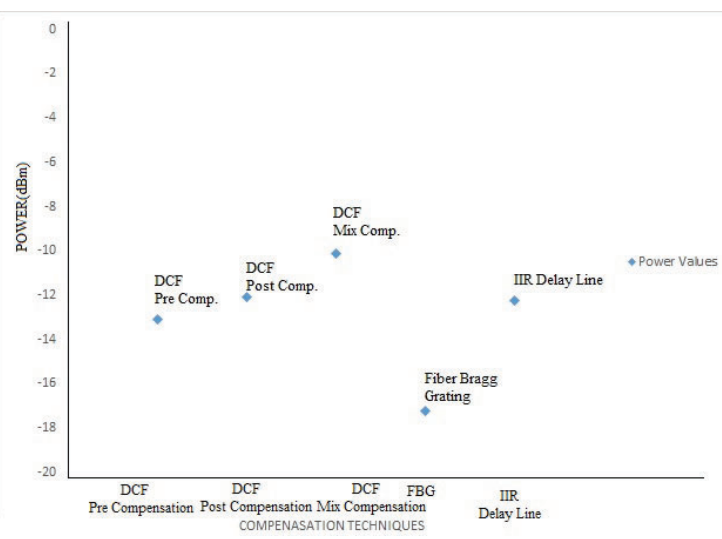

Figure 6: Received Power using various dispersion compensation techniques. 
post compensation, when mixed compensation is used it can produce better results. But, that has been avoided as mix compensation technique can increase the complexity of the system. Figure 6 shows the received power when different compensation techniques are used.

Table 4: Comparison of BER pattern for DLF using FBG and DLF IIR Filter.

\begin{tabular}{l}
$\begin{array}{l}\text { Dispersion } \\
\text { Compensation }\end{array}$ \\
\hline $\begin{array}{l}\text { Q-factor } \\
\text { Brager }\end{array}$
\end{tabular}

Table 5: Distance of Transmission vs Eye Height in DLF IIR Filter

\begin{tabular}{|l|c|}
\hline Distance & Eye-Height \\
\hline $20 \mathrm{~km}$ & 0.003785 \\
\hline $40 \mathrm{~km}$ & 0.001431 \\
\hline $80 \mathrm{~km}$ & 0.000205 \\
\hline $120 \mathrm{~km}$ & $2.9576 \times 10^{-5}$ \\
\hline $160 \mathrm{~km}$ & $3.735 \times 10^{-6}$ \\
\hline
\end{tabular}

The eye pattern for the fiber Bragg grating and delay line IIR filter is explained in the Table 3. Table 5. Compares the distance of transmission with eye height in DLF IIR Filter. Performance of DLF IIR filter has been demonstrated in Figure 7.

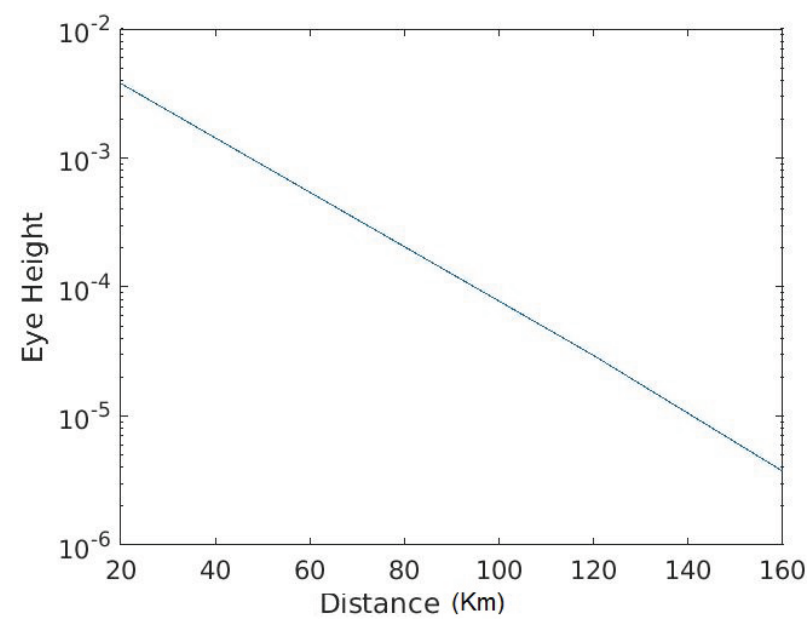

Figure 7: Distance of Transmission vs Eye-Height in DLF IIR Filter

\section{Conclusions}

A communication channel with laser source, NRZ waveform which is generated from the binary values of PRBS at length of 128 bits, is provided to the Mach Zehnder modulator with the single-mode fiber at the data rate of $10 \mathrm{Gbps}$ for $120 \mathrm{~km}$ fiber is investigated. Initially, communication using single-mode fiber without any compensation schemes are analyzed, which shows when a signal travels for the longer distance it leads to the pulse spreading that results in dispersion. Dispersion compensation simulation is performed using various schemes and the performance has been compared. The most commonly used dispersion compensation techniques are pre, post and mix compensation. The performance comparison of these techniques is given in Table 2. Since there is more possibility of occurrence of dispersion in the receiver end, post compensation technique offers Q-factor of 4.96922 that gives better result compared with the pre-compensation technique. Mix compensation offers Q-factor of 5.7533 which is $13.5 \%$ greater than post compensation due to the compensation of the dispersion on both transmitter and receiver side of the optical link. The BER of the pre compensation is $4.71181 \times 10^{-7}$ which results of greater dispersion compensation, on comparing with the other compensation techniques.

Whereas the mix compensation scheme offers less bit error rate of $4.23322 \times 10^{-9}$ compared with the other two dispersion compensation schemes for the same optical link. Fiber Bragg grating also shows the effective result in the dispersion compensation compared with dispersion compensation using dispersion compensating fiber are next investigated. Ideal dispersion compensator FBG is used to provide effective Q-factor of 6.16313 which is $6.65 \%$ greater performance than Mix compensation and also offers a bit error rate of about $3.56 \times 10^{-10}$. This is because of low insertion loss. Finally, the delay line filters in dispersion compensation are also discussed. The IIR filter delay line is used to achieve better performance than other compensation techniques. The effective result can be achieved by the possible utilization of the feedback loops. On comparing the performance of the delay line filter with the other techniques, it is found that the Q-factor for delay line IIR filter of 11.08 which is $47.18 \%$ greater than Fiber Bragg grating and provides a minimum BER of 6.8 $x$ 10^-29. Also, the IIR filter gives $50.7 \%$ higher Q-factor than Mix compensation schemes. So that the performance of delay line filters is efficient than other dispersion compensation schemes. In this work, a novel DLF IIR filter is designed, and performance of the filter is compared with other compensation techniques. The cost of implementing IIR filters to compensate dispersion is minimal compared with pre, post and mix com- 
pensation techniques used in optical systems because the components used to design the dispersion compensation fibers are expensive.

\section{Conflict of Interest}

The authors declare no conflict of interest.

The founding sponsors had no role in the design of the study; in the collection, analyses, or interpretation of data; in the writing of the manuscript, and in the decision to publish the results

\section{References}

1. Zhang Hongbin, Qiu Kun.: Emulation of characteristics of optical fiber transmission for a $10 \mathrm{~Gb} / \mathrm{s}$ single channel situation. Acta photonicasinica. 30(6)715-720. (2001). http://www.photon.ac.cn/ EN/Y2001/V30/16/715

2. M. Vidmar, "Optical-Fiber Communications: Components and Systems", Informacije MIDEM, vol. 31 (2001), no. 4, pp. 246-251. http:// www.midemdrustvo.si/Journal\%20papers/ MIDEM_31(2001)4p246.pdf

3. B. Batagelj, V. Janyani and S. Tomazic, "Research challenges in optical communications towards 2020 and beyond ", Informacije MIDEM, vol. 44 (2014),no. 3, pp. 177-184. http:// www.midemdrustvo.si/Journal\%20papers/ MIDEM_44(2014)3p177.pdf

4. M. Secondini, E. Forestieri, and G. Prati.: Adaptive minimum MSE controlled PLC optical equalizer for chromatic dispersion compensation. IEEE Journal of Lightwave Technology 21(10), 23222331(2003). https://www.osapublishing.org/abstract.cfm?uri=JLT-21-10-2322

5. Li, L.; Yi, X.; Song, S.; Chew, S.X.; Minasian, R.; Nguyen, L. Microwave Photonic Signal Processing and Sensing Based on Optical Filtering. Appl. Sci. 2019, 9, 163.

https://doi.org/10.3390/app9010163

6. P. Prakash, S. Arul Prakash, Ganesh Madhan : Design of All Pass Filter based Modulation Format Conversion with Dispersion Compensation. Tierärztliche Praxis Vol 40, 2020. https://tierarztliche.com/gallery/v40.63.pdf

7. K. Zhong, X. Zhou, J. Huo, C. Yu, C. Lu and A. P. T. Lau, "Digital Signal Processing for Short-Reach Optical Communications: A Review of Current Technologies and Future Trends," in Journal of Lightwave Technology, vol.36, no. 2, pp. 377-400, 15 Jan.15, 2018 https://doi.org/10.1109/JLT.2018.2793881
8. Kakkar, A.; Rodrigo Navarro, J.;Schatz, R.; Pang, X.; Ozolins, O.; Louchet, H.; Jacobsen, G.; Popov, S. Equalization Enhanced Phase Noise in Coherent Optical Systems with Digital Pre- and Post-Processing. Photonics 2016, 3, 12.

https://doi.org/10.3390/photonics3020012

9. R. I. Killey, P. M. Watts, V. Mikhailov, M. Glick and P. Bayvel, "Electronic dispersion compensation by signal predistortion using digital Processing and a dual-drive Mach-Zehnder Modulator," in IEEE Photonics Technology Letters, vol. 17, no. 3, pp. 714-716, March 2005.

https://doi.org/10.1109/LPT.2004.840999

10. M. A. Ilgaz, et al.,"A flexible approach to combating chromatic dispersion in a centralized $5 \mathrm{G}$ network", Opto-Electronics Review, 2020, Vol. 28, No. 1, pp. 35-42

https://doi.org/10.24425/opelre.2020.132498

11. Agrawal, Govind P."Dispersion Management", Fiber-optic communication systems, Vol. 222. John Wiley \&Sons, 2012.

https://doi.org/10.1002/9780470918524.ch8

12. P.Kasthuri, P.Prakah "Performance Analysis of Delay Line Filter using X-Coupler and Delay Line IIR Filter" 2017 4th International Conference on Signal Processing, Communications and Networking (ICSCN -2017), March 16 - 18, 2017, Chennai, India.

https://doi.org/10.1109/ICSCN.2017.8085716

13. Peucheret, Christophe, et al. "Optimization of preand post-dispersion compensation schemes for 10-Gbits/s NRZ links using standard and dispersion compensating fibers." IEEE Photonics Technology Letters 12.8 (2000): 992-994.

https://doi.org/10.1109/68.867985

14. Dhawan, Divya, and Neena Gupta. "Optimization of fiber based dispersion compensation in RZ and NRZ data modulation formats." Journal of Engineering Science and Technology 6.6 (2011): 651-663. http://jestec.taylors.edu.my/ Vol\%206\%20lssue\%206\%20December\%2011/ Vol_6_6_651_663_divyadhawan.pdf

15. Bellotti, Giovanni, Alain Bertaina, and Sébastien Bigo. "Dependence of self-phase modulation impairments on residual dispersion in $10-\mathrm{Gb} / \mathrm{s}$ based terrestrial transmissions using standard fiber." IEEE Photonics Technology Letters 11.7 (1999): 824-826. https://doi.org/10.1109/68.769720

16. Kaler, R. S., Ajay K. Sharma, and T. S. Kamal. “Comparison of pre-, post-and symmetrical-dispersion compensation schemes for $10 \mathrm{~Gb} / \mathrm{s}$ NRZ links using standard and dispersion compensated fibers." Optics Communications 209.1-3 (2002): 107-123. https://doi.org/10.1016/S0030-4018(02)01636-X 
17. Sharma, Ajay K., S. K. Wadhwa, and T. S. Kamal. "Post-dispersion compensation for 10-Gbit/s RZ, Gaussian, and NRZ pulses for indirect modulated optical links using standard fiber and FBG." Optical Transmission Systems and Equipment for WDM Networking III. Vol. 5596. International Society for Optics and Photonics, 2004. https://doi.org/10.1117/12.579505

18. Kaler, R. S., et al. “Power penalty analysis for realistic weight functions using differential time delay with higher-order dispersion." Optical Fiber Technology 8.3 (2002): 240-255.

https://doi.org/10.1016/S1068-5200(02)00009-3

19. Singh, Manjit, Ajay K. Sharma, and R. S. Kaler. "On duty cycle selection of RZ optical pulse to optimize the performance of dispersion compensated 10 Gbps single channel optical communication system using dispersion compensating fibers." Optik 121.8 (2010): 689-695.

https://doi.org/10.1016/j.ijleo.2008.10.001

20. Hu, Bo-ning, et al. "Analysis on Dispersion Compensation with DCF based on Optisystem." 2010 2nd international conference on Industrial and Information Systems. Vol. 2. IEEE, 2010.

https://doi.org/10.1109/INDUSIS.2010.5565685

21. Litchinitser, Natalia M., Benjamin J. Eggleton, and David B. Patterson. "Fiber Bragg gratings for dispersion compensation in transmission: theoretical model and design criteria for nearly ideal pulse recompression." Journal of Lightwave Technology15.8 (1997): 1303-1313.

https://doi.org/10.1109/50.618327

22. Wei, Lee, and John WY Lit. “Design optimization of flattop interleaver and its dispersion compensation." Optics Express15.10 (2007): 6439-6457.

https://doi.org/10.1364/OE.15.006439\

23. Hill, Kenneth O., and Gerald Meltz. "Fiber Bragg grating technology fundamentals and overview." Journal of lightwave technology 15.8 (1997): 1263-1276.

https://doi.org/10.1109/50.618320

24. Kaiser,Gred, "WDM Concepts and Components", Optical Fiber communications 4th Ed.New York, McGraw Hill. http://www.mhhe.com/engcs/electrical/keiser/

25. T. Duthel et al. :Quasi-analytic synthesis of non recursive optical delay line filters for reliable compensation of dispersion effects. IEEE Journal of Lightwave Technology. 24(11), 4403-4410(2006). https://www.osapublishing.org/jlt/abstract. cfm?URI=jlt-24-11-4403

26. P. Prakash and M. Ganesh Madhan.: A Fifth Order FIR Optical Delay Line Filter for Dispersion Compensation. International Conference on Emerging Trends in Electrical, (2012). https://www.researchgate.net/publication/277014520_A_fifth_order_
FIR_optical_delay_line_filter_for_Dispersion_ compensation

26. P. Pavithra, P. Prakash and M. Ganesh Madhan: Analysis on Dispersion Compensation with DelayLine Filter (DLF) using 2x2 Coupler. 5th National Conference on Signal Processing Communications \& VLSI Design (NCSCV 13), 10th \& 11 th May,(2013). https://www.researchgate.net/publication/277014078

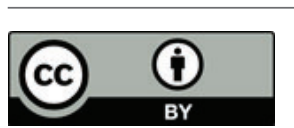

Copyright $\odot 2020$ by the Authors. This is an open access article distributed under the Creative Commons Attribution (CC BY) License (https://creativecommons.org/licenses/by/4.0/), which permits unrestricted use, distribution, and reproduction in any medium, provided the original work is properly cited.

Arrived: 22. 09. 2020

Accepted: 29. 12. 2020 